\title{
Dinâmica espaço-temporal do uso de solo da terra da microrregião na Campanha Central do Rio Grande do Sul entre os anos de 1992 e 2010
}

\author{
Temporal and spatial dynamics of the soil usage in the micro-region of Campanha Central do Rio Grande do Sul \\ between the years of 1992 and 2010.
}

\author{
Daiana Iris Soto Brites', Emanuel Araújo Silva', Laura Camila de Godoy Goergen', \\ Matheus Mesquita da Costa Nunes', Rudiney Soares Pereira' \\ ' Universidade Federal de Santa Maria (UFSM), , Santa Maria, RS, Brasil
}

\begin{abstract}
Resumo
Este artigo tem como objetivo apresentar a evolução temporal ocorrida no uso do solo nos anos de 1992 e 2010 na microrregião da Campanha Central do Rio Grande do Sul, dando destaque para a transição das florestas. A partir de imagens do sensor TM da plataforma Landsat 5 e do aplicativo Spring 5.1.8, foi realizada a classificação das imagens, determinando as seguintes classes de uso do solo: solo exposto, água, uso agrícola, areia, mata nativa e plantação de florestas. Para a geração dos mapas temáticos foi utilizado a Análise LEGAL (Linguagem Espacial para Geoprocessamento Algébrico), ferramenta que possibilita análises espaciais através de álgebra de mapas. A partir da geração dos mapas temáticos foram calculadas as áreas em que ocorreu a expansão de florestas nativas (7,55\% da área total) - áreas em que ocorreu a regeneração natural, tornando-se floresta em 2010. A área em que se manteve o uso de floresta nativa ao longo de 18 anos representa $2,83 \%$ da área total. O desmatamento, áreas que pertenciam a floresta nativa e foi revertido para outro uso, representa 1,23\%. O reflorestamento, representado pelas áreas que passaram a pertencer à classe floresta plantada, foi quantificado em $0,57 \%$ da área total da microrregião. As demais transições de uso $(86,98 \%$ da área total) ocorreram entre as demais classes de uso do solo. O trabalho permitiu observar as mudanças ocorridas no uso do solo em um período de 18 anos, em que foi observado um aumento na área de florestas, tanto nativas como plantadas. Esse aumento está provavelmente associado ao investimento no setor florestal na região a partir de 2005, acompanhado do abandono de terras de difícil manejo e ao aumento do rigor da legislação.
\end{abstract}

Palavras-chaves: Dinâmica espacial, uso de cobertura da terra, Landsat 5, monitoramento ambiental.

\begin{abstract}
This article aims to present the temporal evolution occurred on soil use in 1992 and 2010 in the microregion Central Campaign of Rio Grande do Sul, giving prominence to forests' transition. The images from the Landsat TM sensor platform 5 and the Spring application, was classified images, determining the following land use classes: bare soil, water, agricultural use, sand, native forest and plantation forests. For the generation of thematic maps was used to LEGAL Analysis (GIS Spatial Algebraic Language), tool that enables spatial analysis using map algebra. From the generation of thematic maps were calculated areas where there was the expansion of native forests $(7.55 \%$ of total area) - areas where natural regeneration has occurred, becoming forest in 2010. The area that has remained the use of native forest over 18 years is $2.83 \%$ of the total area. Deforestation, forest areas belonging to native and has reverted to another use, is $1.23 \%$. Reforestation, represented by the areas that now belong to the class planted forest was quantified at $0.57 \%$ of the total area of microregion. The remaining land use change ( $86.98 \%$ of total area) were among the other classes of land use. The work allowed us to observe the changes in land use over a period of 18 years, it was observed an increase in forest area, both native and planted. This increase is probably related to the investment in the forest sector in the region since 2005, accompanied by the abandonment of land unwieldy and increase the rigor of the law.
\end{abstract}

Keywords: Dynamic Spatial, Land Use Cover, Landsat 5, environmental monitoring. 


\section{I.INTRODUÇÃO}

As grandes transformações da paisagem natural ocorridas nas últimas décadas têm aumentado a preocupação da sociedade com as mudanças ambientais globais. Cada vez mais é preciso conservar os recursos naturais existentes preservando a biodiversidade e o equilíbrio entre os ecossistemas. Para isso, o monitoramento do uso e da cobertura da terra torna-se uma tarefa essencial para o conhecimento da realidade ambiental da região estudada e para contribuir na busca de soluções de problemas.

Segundo Grigio (2003), os sistemas e técnicas de sensoriamento remoto podem permitir o estudo da evolução ambiental de uma região, através de análises multitemporais, estabelecendo comparações de uma mesma paisagem entre dois ou mais períodos, podendo desta forma, auxiliar no monitoramento ambiental da região. A utilização de imagens de satélite de média resolução, disponíveis gratuitamente, para a elaboração dos mapas temáticos constitui uma forma econômica de obtenção de dados confiáveis e adequada ao uso no planejamento rural ou urbano. As técnicas do sensoriamento remoto possibilitam o monitoramento de uso de cobertura do solo, visando preservar a biodiversidade e o meio ambiente.

Nesse contexto, o objetivo principal deste trabalho foi a classificação do uso e cobertura da terra na microrregião da Campanha Central do Rio Grande do Sul no período de 1992 a 2010, utilizando para isso imagens do sensor TM do satélite LANDSAT 5, a fim de compreender as mudanças no uso da terra, observar as áreas de floresta, em função da quantificação destas áreas e monitorar a transição das florestas nesta região.

\section{METODOLOGIA DE TRABALHO}

\section{I Localização e caracterização da área de estudo}

A Campanha Central está localizada na Mesorregião Geográfica Sudoeste Rio-Grandense, formada pelos Municípios de: Santana do Livramento, Rosário do Sul, Santa Margarida do Sul e São Gabriel (Figura 1).

A Microrregião apresenta uma precipitação anual em torno de $1372 \mathrm{~mm}$ e uma temperatura média anual de $18,1^{\circ} \mathrm{C}$. O clima é do tipo $\mathrm{Cfa}$ clima subtropical, úmido sem estiagem, segundo a classificação de Köppen (MALUF, 2000).

A Campanha Central faz parte do bioma

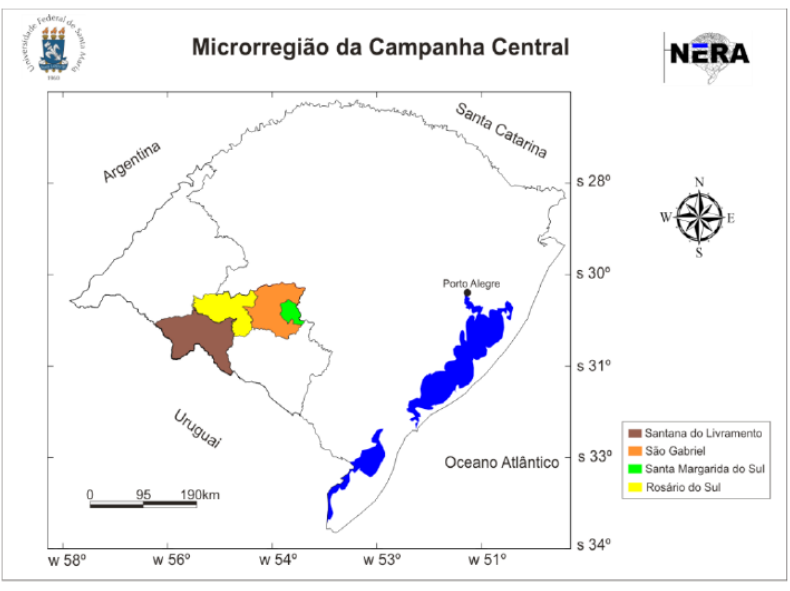

Figura 1. Mapa da Microrregião da Campanha Central MRG 030 (IBGE). Fonte: Spring 4.3.3. Org.: ALVES, A. L. P.; RIFFEL, E. S., 2010

Pampa e possui uma área em torno de 17.295,821 $\mathrm{km}^{2}$, o que corresponde a $6,14 \%$ do estado. Com o aumento da atividade silvícola no estado na última década o Bioma Pampa apresenta-se com grande potencial para a exploração florestal e essa tem sido uma das estratégias para o desenvolvimento da região. Caracterizada pelo relevo com coxilhas e vegetação de gramíneas, a economia da região baseia-se no setor agrossilvopastoril. Ressalta-se que esta atividade econômica permanece na atualidade como a principal atividade do setor primário, pois a criação de gado, na Campanha Gaúcha, e em específico a Campanha Central, se constitui em um dos seus alicerces econômicos. Tal fato justifica a relevância da pecuária, pois essa se mantém como uma importante atividade econômica em âmbito regional, mesmo diante das crises que esse segmento produtivo tem enfrentado no decorrer do tempo. (RODRIGUES, 2006).

\section{I.I Procedimentos operacionais}

Para o desenvolvimento do trabalho foram utilizadas imagens do sensor TM do satélite Landsat 5, disponíveis gratuitamente no site do Instituto Nacional de Pesquisas Espaciais (INPE 2012). O sensor TM possui uma resolução espacial de 30 metros, e uma largura de faixa imageada de $185 \mathrm{~km}$. Para abranger toda a Microrregião da Campanha Central foram necessárias 3 cenas, duas referentes a órbita 223 , pontos 81,82 e uma referente a órbita 224, ponto 81 (Tabela 1 ).

Procurou-se utilizar imagens do mesmo período para as diferentes datas estudadas com 
Tabela 1. Imagens do sensor TM utilizadas.

\begin{tabular}{c|c|c|c}
\hline Satélite & Sensor & Órbita-Ponto & Datas \\
\hline LANDSAT-5 & TM (Thematic Mapper) & $223-081$ & $26 / 12 / 2010$ e $21 / 10 / 1992$ \\
LANDSAT-5 & TM (Thematic Mapper) & $223-082$ & $26 / 12 / 2010$ e $21 / 10 / 1992$ \\
LANDSAT-5 & TM (Thematic Mapper) & $224-081$ & $01 / 12 / 2010$ e $13 / 11 / 1992$ \\
\hline
\end{tabular}

o objetivo de minimizar a variação do ângulo de incidência solar e de fatores associados a sazona lidade tais como condições atmosféricas, umidade de solo e uso de cobertura da terra.

Para a realização do trabalho foi utilizado o software SPRING 5.1.8, foi criado um banco de dados e um projeto com a definição da projeção geográfica, sistema de referência e um retângulo envolvente que recobrisse a área de estudo. Importadas as imagens, foi realizada a correção geométrica através da obtenção de pontos de controle bem distribuídos na área de estudo, admitindo-se um erro máximo de um pixel. Foram elaboradas as composições falsa-cor e cor verdadeira RGB (Red, Green e Blue), a partir das cinco bandas espectrais do sensor (TM1, TM2, TM3, TM4 e TM5). Logo após, foi aplicado a técnica de contraste linear para realce das características da imagem, com o intuito de extrair o máximo de informações das imagens. A técnica utilizada neste estudo baseia-se no algoritmo MaxVer (Máxima Verossimilhança), que agrupa os pixels que aproximadamente pertencem a uma mesma classe de interesse, o qual o resultado é tanto melhor quanto maior o número de pixels em uma amostra de treinamento (PREVIDELLI, 2004).

Para caracterizar os pixels que foram agrupados, foi utilizada a classificação digital e selecionada amostras que apresentavam padrões semelhantes para caracterização dos diferentes usos do solo: Utilização agrícola, água, solo exposto, floresta nativa e floresta plantada.

A composição falsa-cor RGB com as bandas espectrais 5 , 4 e 3 , respectivamente, está representada na figura 2 .

Para analisar a classificação tornou-se necessária a utilização de métodos para a medida de exatidão. Entre os métodos mais utilizados está o coeficiente de concordância Kappa, por retirar do cálculo do índice da classificação correta a parte referente à alocação puramente aleatória das classes (GABOARDI, 2003).

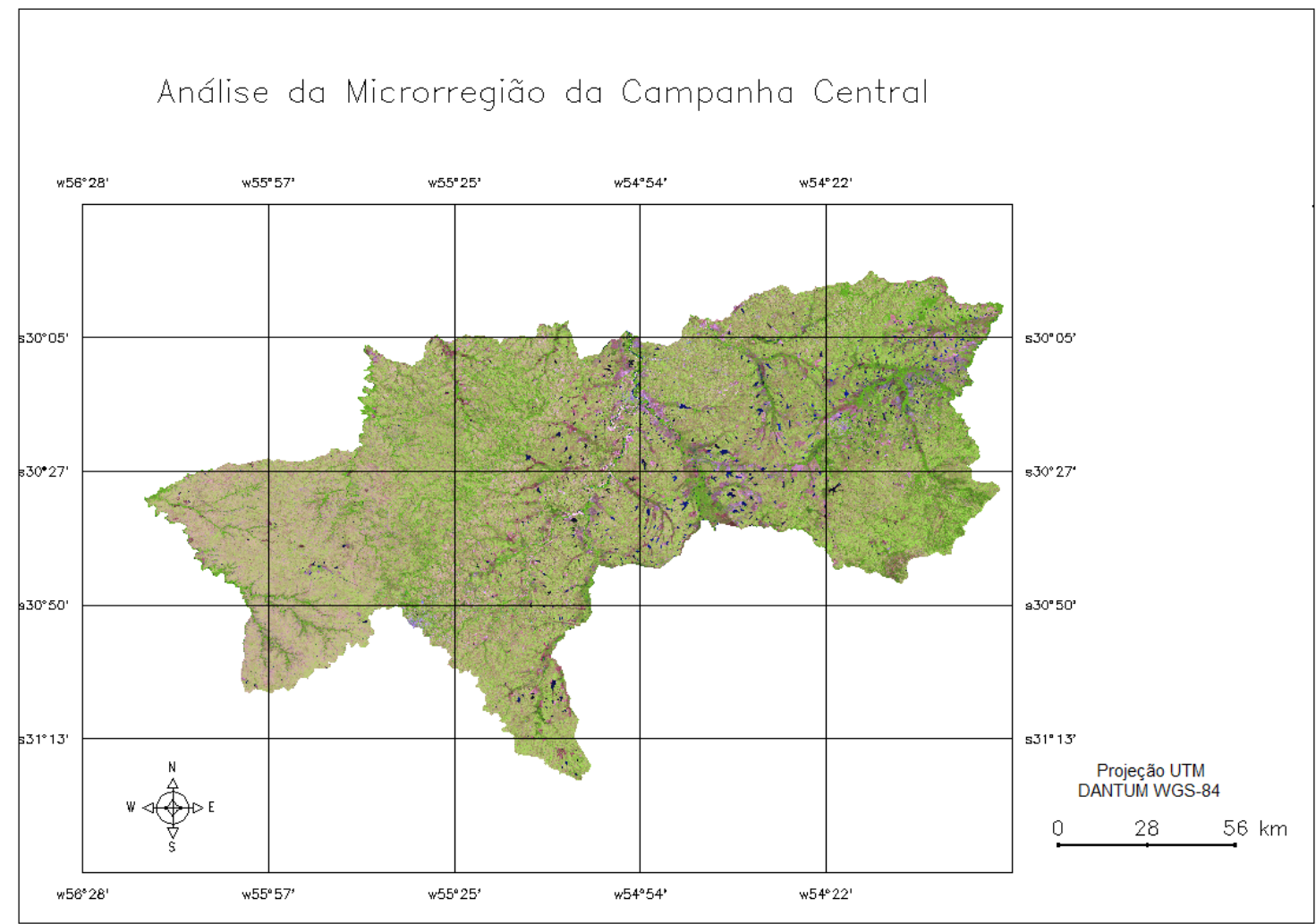

Figura 2. Mosaico das cenas Landsat-5 em composição RGB (543) da Microrregião da Campanha Central, RS. 
Tabela 2- Qualidade da classificação segundo intervalos do coeficiente Kappa.

\begin{tabular}{c|l}
\hline Valor Kappa & Qualidade da classificação \\
\hline$<0,00$ & Péssima \\
$0,00-0,20$ & Ruim \\
$0,20-0,40$ & Razoável \\
$0,40-0,60$ & Boa \\
$0,60-0,80$ & Muito Boa \\
$0,80-1,00$ & Excelente \\
\hline
\end{tabular}

Fonte: Landis e Koch (1977)

Para indicar a qualidade da classificação foi utilizado como base a tabela de Landis e Koch (1977), que possuí valores de qualidade do coeficiente de Kappa, conforme tabela 2.

Foram gerados mapas temáticos a fim de fornecer informações sobre a transição de florestas no decorrer dos anos de 1992 até 2010. Para isso, foi utilizada uma ferramenta que possibilita a realização de análises espaciais através de álgebra de mapas chamada Análise LEGAL (Linguagem Espacial para Geoprocessamento Algébrico). A classe areia foi relacionado ao cursos de água situados na microrregião.

\section{RESULTADOS E DISCUSSÃO}

Através da classificação supervisionada das imagens dos anos de 1992 e 2010, foram obtidos os mapas de uso e cobertura da terra figuras 3 e 4 .

Para esses mapas, os resultados do coeficiente Kappa foram respectivamente 0,945 $(94,57$ $\%)$ e $0,942(94,17 \%)$, enquadra-se em uma classificação "excelente" de acordo com a Tabela 2. Após o mapeamento das classes temáticas de uso e cobertura da terra, foi possível a quantificação das mesmas conforme mostra a Tabela 3 e a Figura 5 apresenta a evolução destas classes temáticas entre

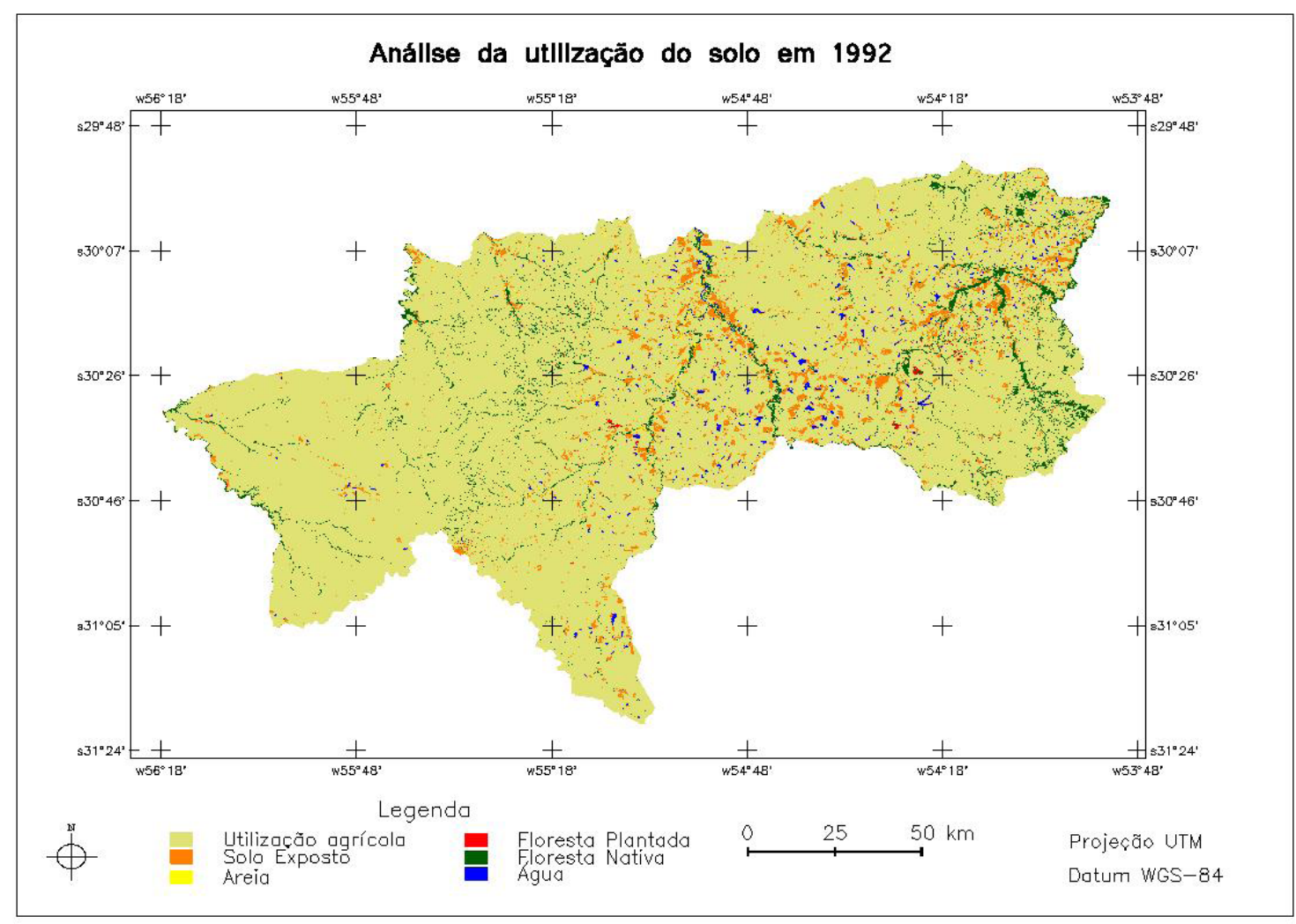

Figura 3. Mapa temático da utilização do solo na microrregião Campanha Central 1992. 


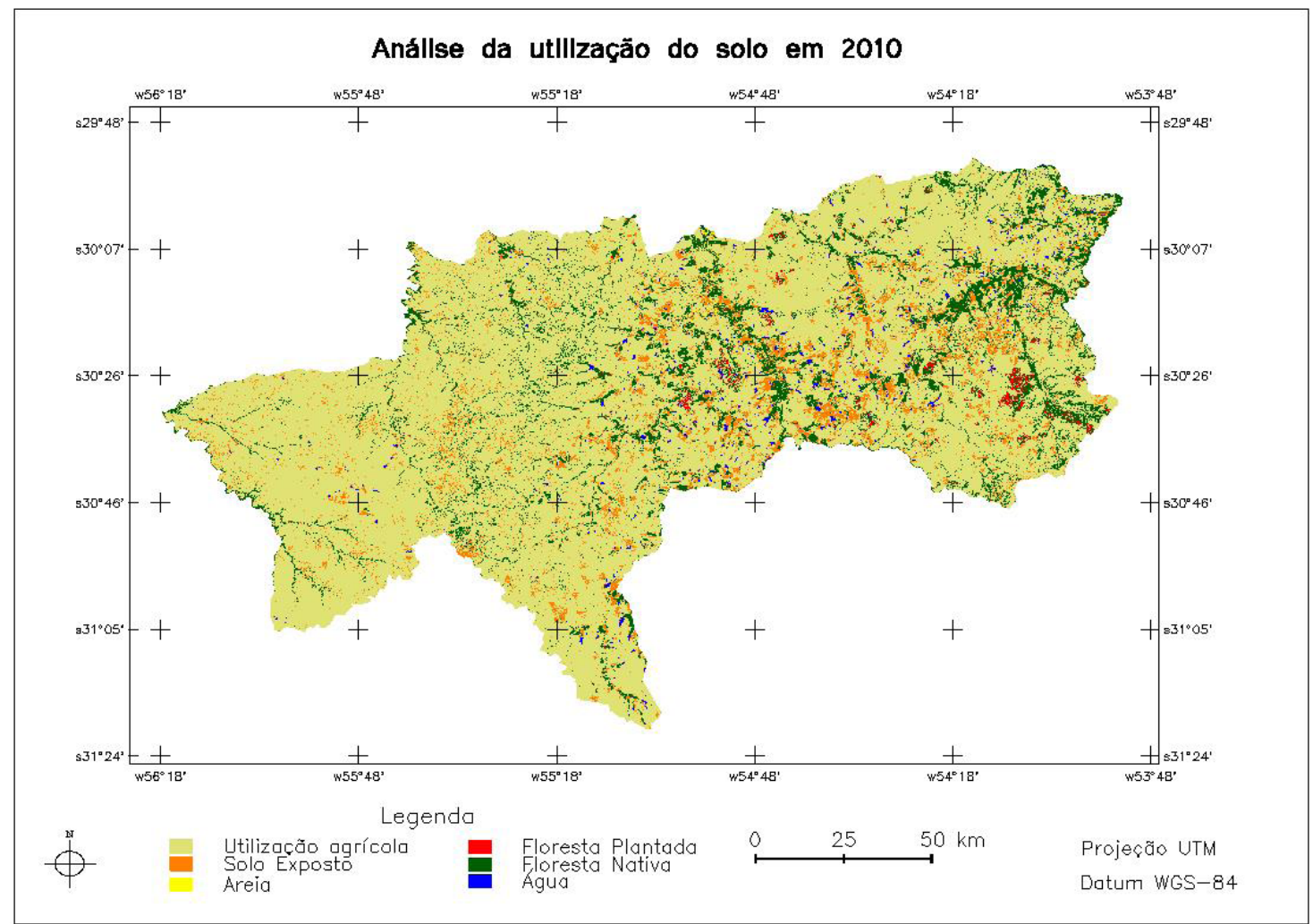

Figura 4. Mapa temático da utilização do solo na microrregião Campanha Central 2010.

Tabela 3. Dados da utilização do solo na Campanha Central.

\begin{tabular}{l|c|c|c|c}
\hline \multirow{2}{*}{ Classe de Uso } & \multicolumn{2}{|c|}{$\mathbf{1 9 9 2}$} & \multicolumn{2}{c}{$\mathbf{2 0 1 0}$} \\
\cline { 2 - 5 } & Área (\%) & Área (ha) & Área (\%) & Área (ha) \\
\hline Água & 0,95 & 19.061 & 0,93 & 18.595 \\
\hline Solo Exposto & 4,99 & 100.632 & 7,52 & 151.526 \\
\hline Areia & 0,20 & 4.080 & 0,10 & 2.103 \\
\hline Floresta Plantada & 0,21 & 4.257 & 0,59 & 11.904 \\
\hline Floresta Nativa & 4,06 & 81.876 & 10,39 & 209.217 \\
\hline Utilização Agrícola & 89,57 & 1.804 .296 & 80,47 & 1.620 .858 \\
\hline Total & $\mathbf{1 0 0 \%}$ & $\mathbf{2 . 0 1 4 . 2 0 5}$ & $\mathbf{1 0 0 \%}$ & $\mathbf{2 . 0 1 4 . 2 0 6}$ \\
\hline
\end{tabular}

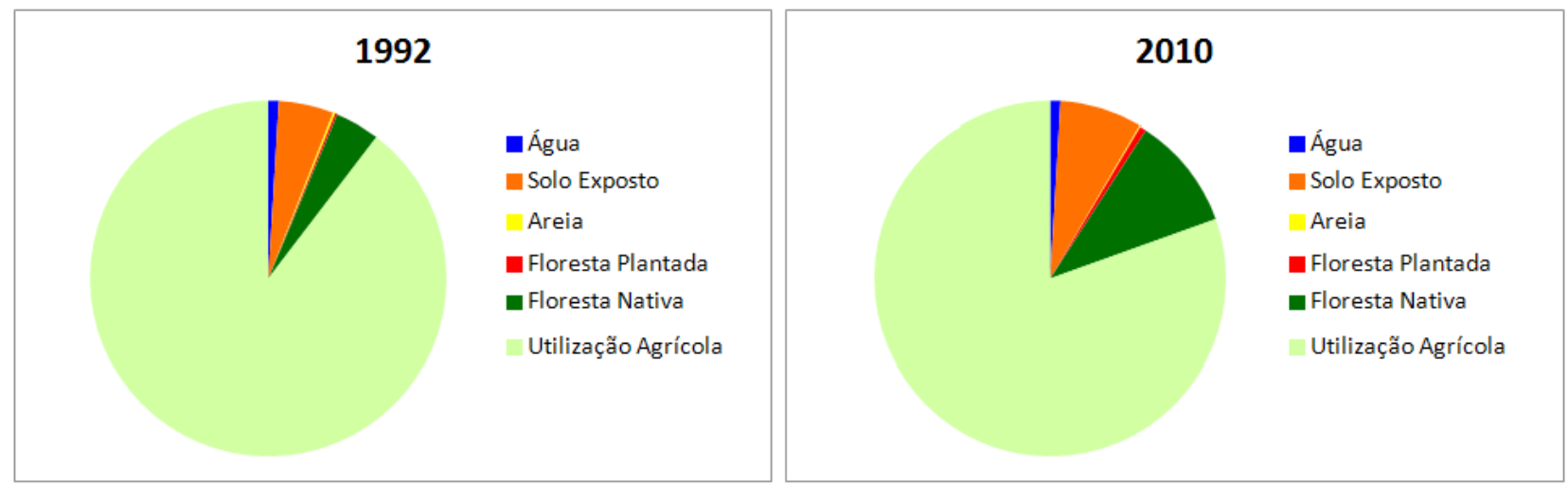

Figura 5. Representação gráfica da Tabela 3 sobre a evolução das classes temáticas para a região de estudo entre os anos de 1992 e 2010. 
os anos de 1992 e 2010. Para ambas as classes de florestas, nativa e plantada, houve um acréscimo de respectivamente $6,33 \%$ e $0,38 \%$ no período de estudo entre 1992 e 2010. A produção no setor de silvicultura e frutífera tem se destacado possuindo um volume na produção de madeira em torno de $172.930 \mathrm{~m}^{3}$ (IBGE 2010). A formação de florestas plantadas (plantações) vem sendo um das estratégias do setor, garantindo acesso a matérias-primas, em quantidades suficientes à escala requerida e de qualidade, pois permite o uso de melhoramento genético e de manejo adequado (ALMEIDA \& SILVA, 1998). Os investimentos de empresas voltadas para processo de celulose auxiliaram na ampliação de florestas, no setor de silvicultura, contribuindo no desenvolvimento da microrregião.

De todas as regiões naturais do Rio Grande do Sul, o Sudoeste é o que mais ostenta o caráter sul-brasileiro, pois a vegetação silvática, só na borda setentrional, chega a se constituir em mata virgem, deixando todo o resto à flora graminácea, sulcada de tênues cordões de galeria" (RAMBO, 1956). A campanha central apresenta grandes extensões de campo, este fator foi introduzido no tema de classificação como utilização agrícola, que apresentou uma redução de 9,1\%. Este dado pode ser explicado devido ao elevado número de êxodo rural que ocorre nos municípios da microrregião. Nas terras abandonadas ocorre a regeneração da vegetação ou muitas vezes, são arrendadas para grandes empresas que visam a produção da silvicultura.

A pecuária é um dos principais fatores econômicos dos municípios que compõem a microrregião. Paralelamente à atividade pecuarista, a partir da década de 1920, estrutura-se, nessa microrregião uma nova configuração espacial, através da inserção da lavoura orizícola. Além da dicotomia produtiva, tem-se uma sociedade dual, composta por pecuaristas e agricultores (SACCOL, NACIMENTO \& BEZZI, 2006). A expansão da lavoura orizícola pode justificar o aumento de solo exposto na região que representou um incremento em torno de 2,53\%.

As áreas de água apresentaram um decréscimo de $0,02 \%$, este valor é inexpressível comparado a área total, e a microrregião apresenta bastantes açudes de pequeno porte, isso compromete a identificação da quantificação de água. A areia também apresentou uma diminuição em torno de $0,10 \%$. Isto pode estar relacionado juntamente pelo mesmo fato da elevada implantação do sistema silvícola na região. Tem-se que utilizar uma vegetação perene e de volumosa estrutura vertical, a floresta propicia o escorrimento da água da chuva pelos troncos e o abrandamento do impacto das gotas na serrapilheira, favorecendo sua lenta infiltração no solo. Tais aspectos são especialmente importantes nos solos arenosos, como os da savana-estépica, muito sensíveis a formação de erosão e voçorocas. A produção de madeira, em uma região carente desta matéria-prima, é outra vantagem a ser destacada, a implantação de florestas em áreas atualmente improdutivas, como os areais, atende, por outro lado, à necessidade de destinar as melhores terras para pastagens ou cultivos agrícolas (MARCHIORI, 1995).

A partir do manuseio da Análise LEGAL, obtiveram-se os resultados das áreas conforme consta na Tabela 4 e Figura 6. Foi possível verificar a transformação dinâmica do solo que se procedeu no decorrer dos anos de 1992 até o ano de 2010 apresentados no mapa da Figura 7.

Na criação do mapa da dinâmica do solo no decorrer destes 18 anos, foram destacadas as transições de florestas na microrregião. A Expansão

Tabela 4.Transição quantitativa da dinâmica do solo nos períodos de 1992-2010 em hectares na microrregião da Campanha Central-RS.

\begin{tabular}{c|c|c}
\hline Classes & Área (ha) & Área (\%) \\
\hline Manutenção de Florestas & 57.031 & 2,83 \\
Nativas & 24.845 & 1,23 \\
Desmatamento & 11.506 & 0,57 \\
Reflorestamento & 152.184 & 7,55 \\
Expansão & 1768.638 & 87,82 \\
Outros Usos & & \\
\hline
\end{tabular}




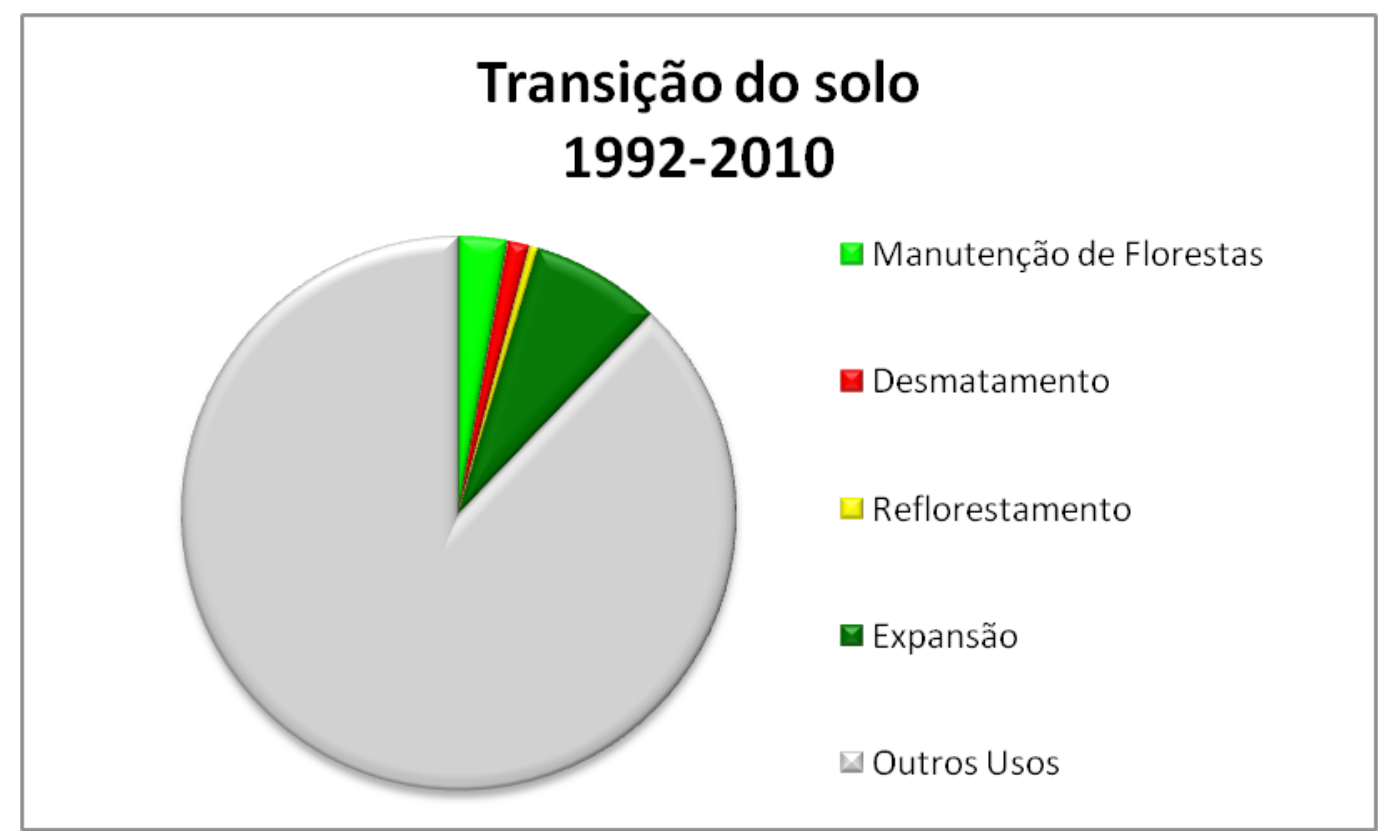

Figura 6. Transição da dinâmica ocorrida na microrregião da Campanha Central no decorrer de 18 anos.

de florestas nativas apresenta $7,55 \%$ da área, isto indica que regiões que não tinham florestas em 1992 passaram a ter, ou seja, o desenvolvimento de regeneração. A manutenção das florestas nativas representa $2,83 \%$ que se mantiveram no período dos 18 anos. O reflorestamento indicou $0,57 \%$ de áreas com florestas plantadas, isto indica o aumento na produção de florestas plantadas. As áreas com desmatamento apresentaram 1,23\% na microrregião, ou seja, florestas nativas que foram retiradas. As transições entre os outros usos, (como: solo exposto, utilização agrícola e areia), não foram objeto de estudos do trabalho.

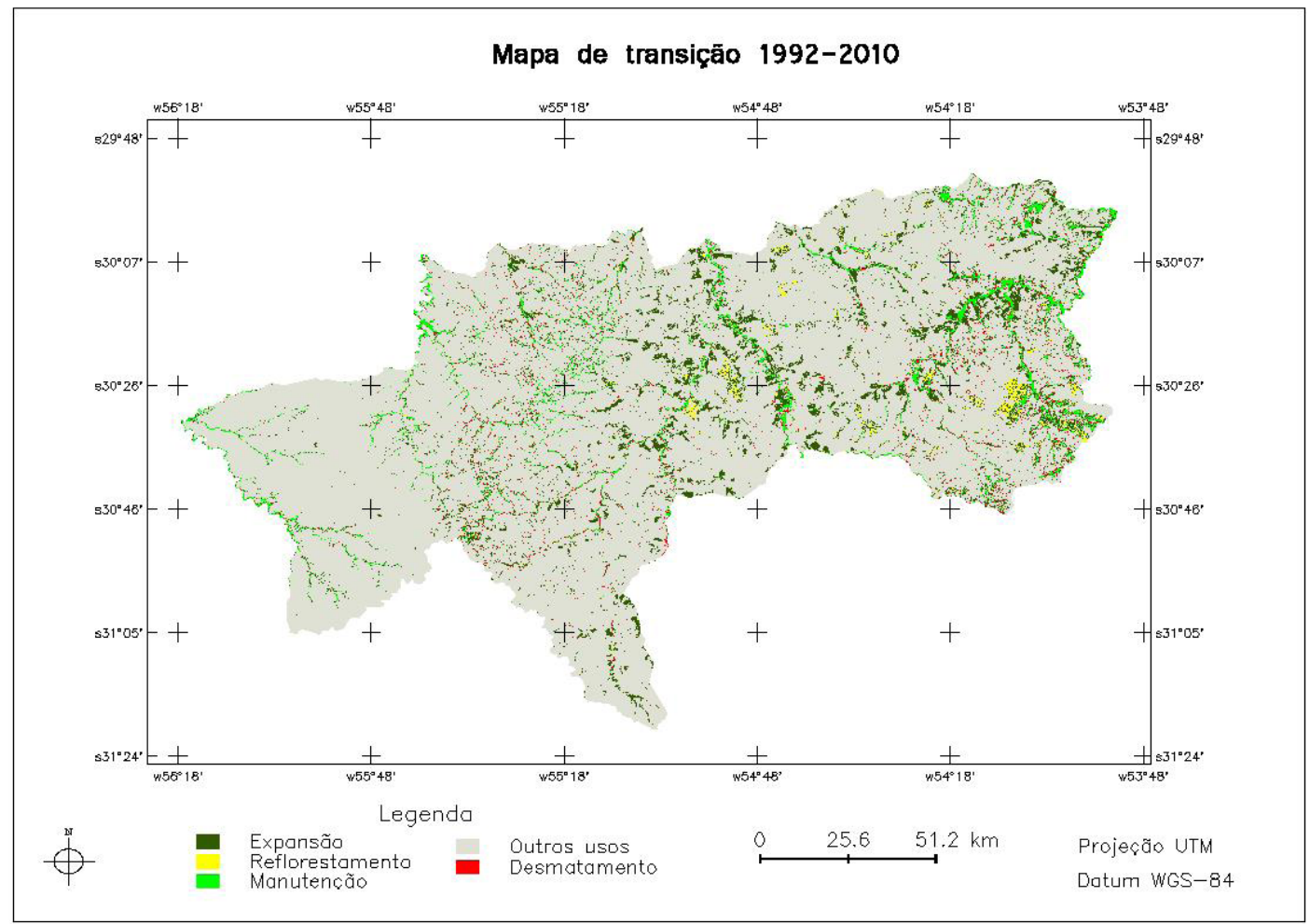

Figura 7. Mapa das transições dos solos de 1992 a 2010 na microrregião Campanha Central. 


\section{CONCLUSÕES}

Pode-se observar a dinâmica espacial da microrregião a partir do mapa temático criado, que representa uma mudança temporal em um período de 18 anos, o que permitiu a quantificação dos temas de uso do solo. Foi observado um aumento nas áreas de florestas, com a Análise LEGAL. O crescimento justifica-se, devido ao investimento de capital na região por empresas interessadas na produção do mercado florestal.

No ano de 1992 a floresta plantada apresentou uma área de 4.257 ha $(0,21 \%)$ em relação a área total da microrregião e no ano de 2010 um acréscimo de 11.904 ha $(0,59 \%)$. Foi possível analisar o aumento de floresta plantada na Análise LEGAL em que a área de reflorestamento representa $0,57 \%$ equivalente a uma área de 11.506 ha. A floresta nativa no ano de 1992, expressa uma área de 81.876 ha $(4,06 \%)$ e em 2010 esta área aumentou para 209.217 ha representando $(10,39 \%)$. Os valores de expansão e manutenção de florestas nativas, obtidos através da Análise LEGAL estão relacionados com o aumento de florestas na microrregião. A área de Manutenção de florestas nativas é $2,83 \%$ da microrregião totalizando uma área de 57.031 ha, e Expansão uma área de 152.184 ha (7,55\%). Pode-se observar que a área de Desmatamento foi de 24.845 ha representando $1,23 \%$ da área total da Campanha Central. Com o sensoriamento remoto foi possível realizar o monitoramento da dinâmica florestal na microrregião da Campanha Central.

\section{AGRADECIMENTOS}

Agradeço a todos do Laboratório de Sensoriamento Remoto (LABSERE) pela ajuda, e ao professor Rudiney por me proporcionar esta oportunidade de aprendizagem.

\section{REFERÊNCIAS BIBLIOGRÁFICAS}

Almeida, J. M. de; SILVA, D. de J. Estratégias para o incremento de competitividade do setor de celulose e papel Brasileiro para o próximo século. In: Congresso de Tecnologia de Fabricação da Pasta Celulósica, 1,1998, São Paulo. Anais eletrônicos... São Paulo, 1998. Disponível em: <http://www.celuloseonline.com.br/pagina/pagina.asp?iditem $=1587>$.
Acesso em: 8 out. 2012.

Alves, A. L. P.; Bezzi, M. L.; Pettine, L. J. A organização espacial da microrregião geográfica da Campanha Central. Artigo de iniciação científica: Eventos CEPE/UNIFRA, 2012. Disponível em: <http://www.unifra.br/eventos/sepe2012/Traba1hos/5970.pdf >. Acesso em: 26 set. 2012.

GABOARDI, C. Utilização da imagem de coerência SAR para classificação do uso da terra: Floresta Nacional do Tapajós. São José dos Campos: INPE. Dissertação de Mestrado, 2003.

Grigio. .A. M. Aplicação de Sensoriamento Remoto e Sistema de Informação Geográfica na determinação da vulnerabilidade natural e ambiental no Município de Guamaré (RN): Simulação de Risco às Atividades da Indústria Petrolífera. Natal. Dissertação (Mestrado em Geodinâmica e Geofísica) - Universidade Federal do Rio Grande do Norte, p. 223. 2003.

IBGE - Instituto Brasileiro de Geografia e Estatística. Disponível em: <http://www.ibge.gov.br>. Acesso em: 28 out. 2012.

INPE -Instituto Nacional de Pesquisas Espaciais. Divisão de Geração de Imagens -DGI. Disponível em: <http://www.dgi.inpe.br/CDSR/>. Acesso em 10 set. 2012 .

Landis, J.; Koch, G. G. The measurements of agreement for categorical data. Biometrics, Washington, v. 33, n. 3, p. 159-179, 1977.

Maluf.T. R. J. Nova classificação climática no estado do Rio Grande do Sul. Revista Brasileira de Agrometeorologia, Santa Maria, v. 8, n. 1, p. 150, 2000.

Marchiori, J. N. C. Vegetação e Areais no Sudoeste Rio-grandense. Revista Ciência \& Ambiente. Santa Maria: Editora da Universidade Federal de Santa Maria, n. 11, p. 81-92, jul./dez. 1995.

Previdelli, I.T.S. Estimadores de máxima verossimilhança corrigidos para modelos superdispersados não lineares. São Carlos: Universidade Federal de Santa Catarina. Tese de Doutorado em Economia, p-000. 2004.

Rambo, B Pe. A Fisionomia do Rio Grande do Sul: ensaio de monografia natural. Porto Alegre: Edição da Livraria Selbach, 1956. 
Rodrigues, A. O latifúndio no Rio Grande do Sul: velhas formas na funcionalidade de novos atores econômicos na Microrregião Geográfica da Campanha Central. 2006. 167 f. Dissertação (Mestrado em Geografia) - Universidade Federal de Santa Maria, 2006.

Saccol, P. T. ; Nascimento, T. F. ; Bezzi, M. L.; et al. RS: uma proposta de regionalização considerando os aspectos geoeconômicos. Relatório Técnico.

(PROADE 2/FAPERGS). Universidade Federal de Santa Maria, 2006. (Inédito). 